\title{
Management of electricity generation using the Taguchi approach
}

\author{
M. Jamil ${ }^{1}$, V. Popov ${ }^{2}$, S. Ahmed ${ }^{2,3}$ \& Z. A. Khan ${ }^{4}$ \\ ${ }^{1}$ Department of Electrical Engineering, Jamia Millia Islamia, \\ New Delhi, India \\ ${ }^{2}$ Wessex Institute of Technology, Southampton, UK \\ ${ }^{3}$ Department of Civil Engineering, Jamia Millia Islamia, \\ New Delhi, India \\ ${ }^{4}$ Department of Mechanical Engineering, Jamia Millia Islamia, \\ New Delhi, India
}

\begin{abstract}
The economic dispatch (ED) is one of the most important operational functions of the modern energy management system. The purpose of the economic dispatch is to find the optimum generation among the existing units, such that the total generation cost is minimized while simultaneously satisfying the power balance equations and various other constraints in the system. The unit commitment or pre-dispatch problem is to select optimally out of the available generating sources to operate in meeting the expected load along with a specified margin of operating reserve over a specified period of time. The other aspect of economic dispatch is to optimize the electricity generation among the generating units actually paralleled with the system in terms of supply of the power system. In this paper, the Taguchi method, a powerful tool for process optimization and design, is used to solve the Energy Dispatch problem in order to minimize the cost function. An orthogonal array, the signal-to-noise $(\mathrm{S} / \mathrm{N})$ ratio and the analysis of variance (ANOVA) are employed to obtain the optimal level of the parameters involved in the cost function. The results obtained are approximately equal to the minimum cost irrespective of the chosen values of the level of parameters and proves that the Taguchi method is insensitive to the choice of initial values for parameters. The optimized result has been verified using the confirmatory test.
\end{abstract}

Keywords: economic dispatch, energy management, optimization, Taguchi approach, analysis of variance. 


\section{Introduction}

The economic dispatch (ED) is one of the most important operational functions of the modern energy management system. The purpose of the economic dispatch is to find the optimum generation among the existing units, so that the total generation cost is minimized while satisfying the power balance equations and other constraints in the system. Economic dispatch involves the optimization at two different aspects. The first one is the unit commitment or pre-dispatch problem wherein it is required to select optimal operation out of the available generating sources to meet the expected load along with a specified margin of operating reserve over a period of time. The second aspect is the on-line economic dispatch i.e. optimizing the generation of power among the parallel generating units to minimize the total cost of supplying of the power system.

Over the past few years, a number of approaches have been used for solving the Economic Dispatch problem for example the lambda iteration method, quadratic programming, and the gradient method [1]. All of these numerical methods for solving the ED problem are based on assumption, that the incremental cost curves of the units are piecewise-linear monotonically increasing function. Some time they may lead to multiple local minimum points of the cost function. Classical dispatch algorithms require that these characteristics be approximated, even though such approximations are not desirable as it may lead to suboptimal operations and hence huge revenue losses over a period of time.

In order to make numerical methods more convenient for solving the economic dispatch problem, artificial intelligence techniques, such as fuzzy logic, neural network and Hopfield neural networks have been also employed to solve the ED as a non-smooth optimization problem. Conventional economic dispatch takes into account incremental production cost equations as deterministic. It means that all input information is known with full certainty and that the optimal plans of dispatch are always realized exactly. But in practice a basic difficulty is that the information that is supposed to be known is not always deterministic. Several inaccuracies and uncertainties lead to deviation from optimal operation. The cost functions are important input data for economic dispatch but the cost function are inaccurate in most of the cases. These inaccuracies are deviations from input information given on the data sheets from their values during actual operation. Recently, a global optimization technique known as genetic algorithm (GA), has been used to solve the power optimization problem. The genetic algorithm may find the several suboptimal solutions with in a realistic computation time. However, some deficiencies are identified in genetic algorithm performance. The premature convergence of GA reduces its search capability that leads to a higher probability towards a local minimum [2]. The choice of the genetic parameters such as Pc (crossover probability), Pm (mutation probability) and $\mathrm{N}$ (population size) are also very subject sensitive.

The method of experimental designs constitutes the ideal complement to obtain the desired optimization as it allows finding out which of the operator is most significant as compared to the others and with what values [3]. The 
Taguchi method has been widely used in experimental designs for problems with multiple parameters where the optimization of an objective function is required [4-8]. The use of the Taguchi method for multi-user detection is a novel idea, and it leads to efficient algorithms that can find a satisfactory solution by maximizing the likelihood function in a small number of iterations. In this paper an attempt has been made to use the Taguchi method in order to solve the economic dispatch problem. The cost function is optimized using the concept of orthogonal array, signal to noise ratio $(\mathrm{S} / \mathrm{N}$ ratio) and analysis of variance (ANOVA) as suggested by Taguchi. The optimized result has been verified using the confirmatory test.

\section{Introduction to Taguchi method}

The Taguchi method is a powerful tool for the design of high quality systems. It provides a simple, efficient and systemic approach to optimize designs for performance, quality, and cost. Taguchi techniques can be used to optimize the performance characteristics through the settings of design parameters and reduce the sensitivity of the system performance to source variation. Taguchi method has many advantages compared with other techniques such as simplification of experiment plan, feasibility of study of interaction between different parameters, lesser number of experiments, reduced cost and time. Taguchi method uses a special design of orthogonal arrays to study the entire parameter space i.e. number of parameters and its levels, with a small number of experiments only and thus, it results in a lot of cost as well as time saving. A desired number of experiments as suggested by the orthogonal array are performed and the experimental results are then transformed into a signal-to-noise $(\mathrm{S} / \mathrm{N})$ ratio. Taguchi recommends the use of $\mathrm{S} / \mathrm{N}$ ratio to measure the quality characteristics deviating from the desired values. Usually, there are three categories of quality characteristic in the analysis of the $\mathrm{S} / \mathrm{N}$ ratio, i.e. the-lower-the-better, thehigher-the-better, and the-nominal-the-better. The $\mathrm{S} / \mathrm{N}$ ratio for each level of process parameters is computed based on the $\mathrm{S} / \mathrm{N}$ analysis. A greater $\mathrm{S} / \mathrm{N}$ ratio corresponds to better quality characteristics regardless of its category. Therefore, the optimal level of the process parameters is the level with the greatest $\mathrm{S} / \mathrm{N}$ ratio. Furthermore, a statistical analysis of variance (ANOVA) is performed to see which process parameters are statistically significant. With the $\mathrm{S} / \mathrm{N}$ and ANOVA analyses, the optimal combination of the process parameters can be predicted. A confirmation experiment is also conducted to verify the optimal process parameters obtained from the study.

\section{Economic dispatch problem formulation}

The majority of electricity generators are of three types-nuclear, hydro and fossil (coal, oil or gases). Nuclear plants tend to be operated at constant output levels and hydro plants have essentially no variable operating costs. Therefore, E.D problem is mainly associated with the fossil fuel based plants. Figure 1 shows a simple model of a fossil plant. The components of cost that fall under the 
category of dispatching procedures are the costs of labour, supplies and maintenance. Generally, costs of labour, supplies and maintenance are fixed as some percentages of fuel costs. As a result, the operating cost of the plant has the form shown in Figure 2. In Economic Dispatch problem the cost function is a very important. For dispatching purpose cost is usually approximated by one or more quadratic segment so that fuel cost curve is modeled as a quadratic in the active power generation. In Figure 2, $\mathrm{P}_{\text {gimin }}$ and $\mathrm{P}_{\text {gimax }}$ are the lower and the upper limits on its output [10].

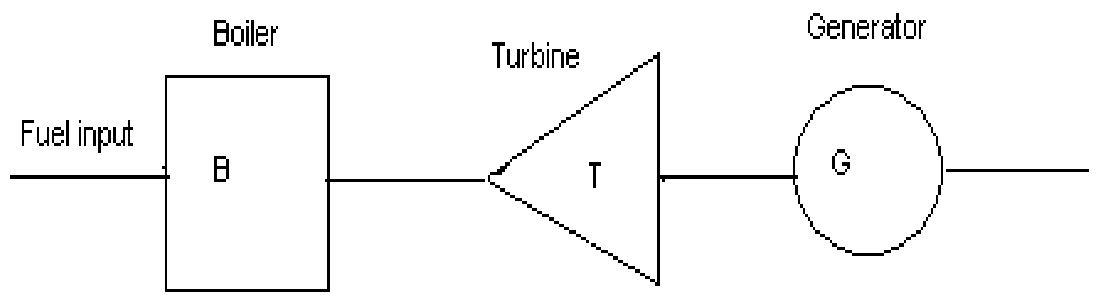

Figure 1: Simple model of a fossil plant.

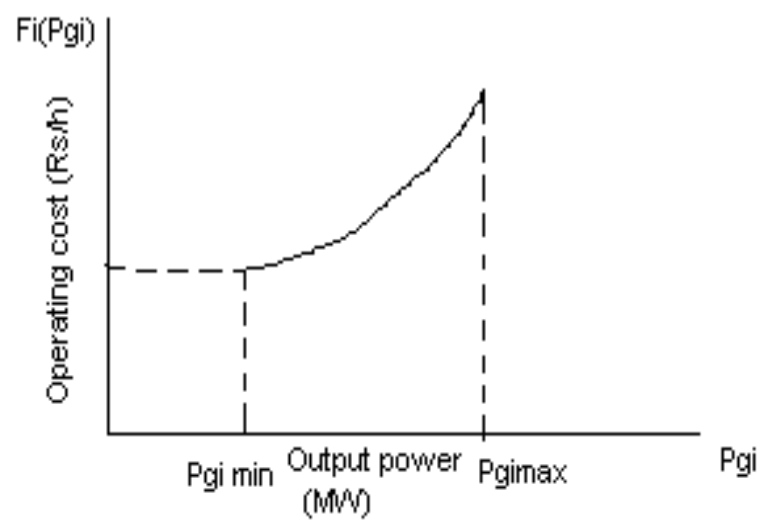

Figure 2: Curve of operating costs of a fossil-fired generator.

The Economic Dispatch problem can be defined as

$$
\text { Minimization of } \quad F\left(P_{g i}\right)=\sum_{i=1}^{N_{G}}\left(a_{i} P_{g i}^{2}+b_{i} P_{g i}+C_{i}\right) \quad \text { Rs/hour }
$$

Subject to the following constraints

(i) The energy balance equation, the sum of all $\mathrm{P}_{\mathrm{gi}}$ should be equal to the total demand plus total transmission loss i.e.

$$
\sum_{i=1}^{N_{G}} P_{g i}=P_{D}+P_{L}
$$

and 
(ii) The inequality constraints

$$
\mathrm{P}_{\text {gi min }} \leq \mathrm{p}_{\text {gi }} \leq \mathrm{P}_{\text {gi max }}
$$

where

$a_{i}$ - Measure of losses in the system

$b_{i}-$ The fuel cost

$\mathrm{c}_{\mathrm{i}}$ - Salary and wages, interest and depreciation

$\mathrm{P}_{\mathrm{D}}$ - the load demand

$\mathrm{P}_{\mathrm{gi}}$ - the real power generation

$\mathrm{N}_{\mathrm{G}}$ - the number of generator

$\mathrm{P}_{\mathrm{L}}$ - the transmission loss

The transmission losses are not considered in the present study.

\section{Optimization of fuel cost}

Following conventional economic dispatch problem discussed in [9] is chosen here to solve by Taguchi approach. For a three-generator system, the fuel cost coefficients and the operating generator limits are given in table I. The power dispatch for loads $160 \mathrm{MW}$ is considered.

Table 1: $\quad$ Fuel cost coefficients and operating generator limits.

\begin{tabular}{|c|c|c|c|c|c|}
\hline $\begin{array}{c}\text { Generator } \\
\mathrm{i}\end{array}$ & $\begin{array}{c}\mathrm{a}_{\mathrm{i}} \\
\left(\mathrm{Rs} / \mathrm{MW}^{2} \mathrm{~h}\right)\end{array}$ & $\begin{array}{c}\mathrm{b}_{\mathrm{i}} \\
(\mathrm{Rs} / \mathrm{MWh})\end{array}$ & $\begin{array}{c}\mathrm{c}_{\mathrm{i}} \\
(\mathrm{Rs} / \mathrm{h})\end{array}$ & $\begin{array}{c}\mathrm{P}_{\mathrm{gi}}{ }^{\min } \\
(\mathrm{MW})\end{array}$ & $\begin{array}{c}\mathrm{P}_{\mathrm{gi}}{ }^{\max } \\
(\mathrm{MW})\end{array}$ \\
\hline 1 & 0.006085 & 10.04025 & 136.9125 & 50 & 100.0 \\
\hline 2 & 0.005915 & 9.760576 & 059.1550 & 60.0 & 150.0 \\
\hline 3 & 0.005250 & 8.662500 & 328.1250 & 55.0 & 250.0 \\
\hline
\end{tabular}

\subsection{Selection of process parameters}

In this paper three parameters namely $\mathrm{P}_{\mathrm{g} 1}, \mathrm{P}_{\mathrm{g} 2}$, and $\mathrm{P}_{\mathrm{g} 3}$ and three levels of each parameter i.e. Level 1, Level 2 and Level 3 have been considered. In order to study the effect of each parameter on the output we have to perform $3^{3}=27$ experiments. But by applying the Taguchi method we can investigate the effect of these parameters in order to obtain optimum level of these parameters by performing less number of experiments i.e. only 9 experiments. Three levels of each parameter were selected as shown in Table II. In order to select these levels it has been assumed that at any point in time the minimum power demand for a particular area is $160 \mathrm{MW}$ and it must be fulfilled. The first level is the minimum limit and third level is the maximum limit and the second level is selected by using following equation

$$
\mathrm{P}_{\mathrm{gi}}=\eta_{\mathrm{k}} \alpha_{\mathrm{i}} \mathrm{P}_{\text {gi ref }}
$$


In equation (4), $\eta_{\mathrm{k}}, \alpha_{\mathrm{i}}$, and $\mathrm{P}_{\mathrm{gi} \text { ref }}$ are calculated from the following equations.

$$
\mathrm{P}_{\text {gi ref }}=0.5 \times\left(\mathrm{P}_{\text {gi min }}+\mathrm{P}_{\text {gi max }}\right)
$$

$\eta_{\mathrm{k}}$ - the shrinking coefficient

$$
\eta_{k}=\frac{P_{D}}{\sum_{i=1}^{N} \alpha_{i} x P_{\text {gi.ref }}}
$$

where, $\alpha \mathrm{i}$ stands for the relative contribution with respect to the grand total of load demand, $\mathrm{P}_{\mathrm{D}}$. In this paper the relative contribution is chosen as $0.5,0.8$, and 1.2 .

$\eta \mathrm{k}$ is determined such that the constraint defined by equation (2) is satisfied. It may be noted that Pgi ref, which is the average of Pgi min and Pgi max, is taken as the reference point for scaling. In this way, the total generation becomes equal to the demand [4].

Table 2: $\quad$ Parameters and their levels.

\begin{tabular}{|c|c|c|c|c|c|}
\hline Symbol & Parameters & Unit & $\begin{array}{c}\text { Level } \\
1\end{array}$ & $\begin{array}{c}\text { Level } \\
2\end{array}$ & $\begin{array}{c}\text { Level } \\
3\end{array}$ \\
\hline $\mathrm{A}$ & $\mathrm{P}_{\mathrm{g} 1}$ & $\mathrm{MW}$ & 50 & 54 & 100 \\
\hline $\mathrm{B}$ & $\mathrm{P}_{\mathrm{g} 2}$ & $\mathrm{MW}$ & 60 & 76 & 150 \\
\hline $\mathrm{C}$ & $\mathrm{P}_{\mathrm{g} 3}$ & $\mathrm{MW}$ & 55 & 110 & 250 \\
\hline
\end{tabular}

\subsection{Orthogonal array experiment}

In order to select an appropriate orthogonal array for the experiments, the total number of degrees of freedom should be known. The degrees of freedom are defined as the number of comparisons between design parameters that need to be made for identification and quantification of better level.

The degrees of freedom of a parameter are equal to the number of level minus 1 (one). Thus the degrees of freedom of parameter $P_{g 1}$ is $(3-1=2)$ and degrees of freedom of parameters $\mathrm{P}_{\mathrm{g} 2}$ and $\mathrm{P}_{\mathrm{g} 3}$ are also 2 each. The degrees of freedom associated with the interaction between two design parameters are given by the product of the degrees of freedom for the two design parameters. In the present study, the interaction between the parameters is neglected. Therefore, there are six degrees of freedom owing to there being three parameters.

Once the required degrees of freedom are known, the next step is to select an appropriate orthogonal array to serve the specific purpose. Basically, the degrees of freedom for the orthogonal array should be greater than or at least equal to those for the design parameters. In this study, an $L_{9}$ orthogonal array with four columns and nine rows was used. This array has eight degrees of freedom and it can handle three-level design parameters. Each parameter is assigned to a column, nine parameter combinations being available. Therefore, only nine 
experiments are required to study the entire parameter space using the $L_{9}$ orthogonal array. The experimental layout for the three parameters using the $L_{9}$ orthogonal array is shown in Table III. Since the $L_{9}$ orthogonal array has four columns, one column of the array is left empty for the error of experiments: orthogonality is not lost by letting one column of the array remain empty.

Table 3: $\quad$ Experimental layout using $L_{9}$ orthogonal array.

\begin{tabular}{|c|c|c|c|c|}
\hline \multirow{2}{*}{$\begin{array}{c}\text { Experiment } \\
\text { number }\end{array}$} & \multicolumn{5}{|c|}{ Parameter level } \\
\cline { 2 - 5 } & $\mathrm{A}$ & $\mathrm{B}$ & $\mathrm{C}$ & $\mathrm{D}$ \\
\cline { 2 - 5 } & $\mathrm{P}_{\mathrm{g} 1}$ & $\mathrm{P}_{\mathrm{g} 2}$ & $\mathrm{P}_{\mathrm{g} 3}$ & Error \\
\hline 1 & 1 & 1 & 1 & \\
\hline 2 & 1 & 2 & 2 & \\
\hline 3 & 1 & 3 & 3 & \\
\hline 4 & 2 & 1 & 3 & \\
\hline 5 & 2 & 2 & 1 & \\
\hline 6 & 2 & 3 & 2 & \\
\hline 7 & 3 & 1 & 2 & \\
\hline 8 & 3 & 2 & 3 & \\
\hline 9 & 3 & 3 & 1 & \\
\hline
\end{tabular}

\subsection{Analysis of the $S / N$ ratio}

In the Taguchi method, the term "signal" represents the desirable value (mean) for the output characteristic and the term "noise" represents the undesirable value standard deviation (SD) for the output characteristic. Therefore, the $\mathrm{S} / \mathrm{N}$ ratio is the ratio of the mean to the $\mathrm{SD}$. Taguchi uses the $\mathrm{S} / \mathrm{N}$ ratio to measure the quality characteristic deviating from the desired value. The $\mathrm{S} / \mathrm{N}$ ratio, $\eta$ is defined as:

$$
\eta=-10 \log \text { (M.S.D.) }
$$

where MSD is the mean-square deviation for the output characteristic.

As mentioned earlier, there are three categories of quality characteristics, i.e. the-lower-the-better, the-higher-the-better, and the-nominal-the better. To minimize the cost function, the-lower-the-better quality characteristic must be taken. The mean-square deviation for the lower-the-better quality characteristic can be expressed as:

$$
\text { M.S.D. }=\frac{1}{m} \sum_{i=1}^{m} S_{i}^{2}
$$

where $m$ is the number of tests and $S_{i}$ is the value of cost for the $\mathrm{i}^{\text {th }}$ test.

Table 4 shows the experimental results for the cost and the corresponding $\mathrm{S} / \mathrm{N}$ ratio using Eqs. (7) and (8). Since the experimental design is orthogonal, it is then possible to separate out the effect of each design parameter at different levels. For example, the mean $\mathrm{S} / \mathrm{N}$ ratio for the $\mathrm{P}_{\mathrm{g} 1}$ at levels 1,2 , and 3 can be calculated by averaging the $\mathrm{S} / \mathrm{N}$ ratio for the experiments $1-3,4-6$, and $7-9$ 
respectively. The mean $\mathrm{S} / \mathrm{N}$ ratio for each level of the other parameters can be computed in the similar manner. The mean $\mathrm{S} / \mathrm{N}$ ratio for each level of the parameters is summarized in Table 5.

Table 4: $\quad$ Output cost and $\mathrm{S} / \mathrm{N}$ ratio for $160 \mathrm{MW}$.

\begin{tabular}{|c|c|c|c|c|c|}
\hline $\begin{array}{c}\text { Experiment } \\
\text { number }\end{array}$ & $\begin{array}{c}\mathrm{P}_{\mathrm{g} 1} \\
(\mathrm{MW})\end{array}$ & $\begin{array}{c}\mathrm{P}_{\mathrm{g} 2} \\
(\mathrm{MW})\end{array}$ & $\begin{array}{c}\mathrm{P}_{\mathrm{g} 3} \\
(\mathrm{MW})\end{array}$ & $\begin{array}{c}\mathrm{F}\left(\mathrm{P}_{\mathrm{gi}}\right) \\
\text { Rs. }\end{array}$ & $\begin{array}{c}\mathrm{S} / \mathrm{N} \text { ratio } \\
(\mathrm{dB})\end{array}$ \\
\hline 1 & 50 & 60 & 55 & 2140.70 & -66.61 \\
\hline 2 & 50 & 76 & 110 & 2833.80 & -69.04 \\
\hline 3 & 50 & 150 & 250 & 5132.30 & -74.20 \\
\hline 4 & 54 & 60 & 250 & 4184.80 & -72.43 \\
\hline 5 & 54 & 76 & 55 & 2352.40 & -67.43 \\
\hline 6 & 54 & 150 & 110 & 3697.70 & -71.35 \\
\hline 7 & 100 & 60 & 110 & 3212.40 & -70.13 \\
\hline 8 & 100 & 76 & 250 & 4858.80 & -73.73 \\
\hline 9 & 100 & 150 & 55 & 3678.60 & -71.31 \\
\hline
\end{tabular}

Table 5: $\quad$ Mean $\mathrm{S} / \mathrm{N}$ ratio.

\begin{tabular}{|l|l|l|l|l|l|}
\hline \multirow{2}{*}{ Symbol } & \multirow{2}{*}{ Parameter } & \multicolumn{4}{|c|}{ Mean S/N Ratio dB } \\
\cline { 3 - 6 } & & Level 1 & Level 2 & Level 3 & max-min \\
\hline $\mathrm{A}$ & $\mathrm{P}_{\mathrm{g} 1}$ & -69.95 & -70.40 & -71.72 & 1.77 \\
\hline $\mathrm{B}$ & $\mathrm{P}_{\mathrm{g} 2}$ & -69.72 & -70.06 & -72.29 & 2.57 \\
\hline $\mathrm{C}$ & $\mathrm{P}_{\mathrm{g} 3}$ & -68.45 & -70.18 & -73.45 & 5.00 \\
\hline
\end{tabular}

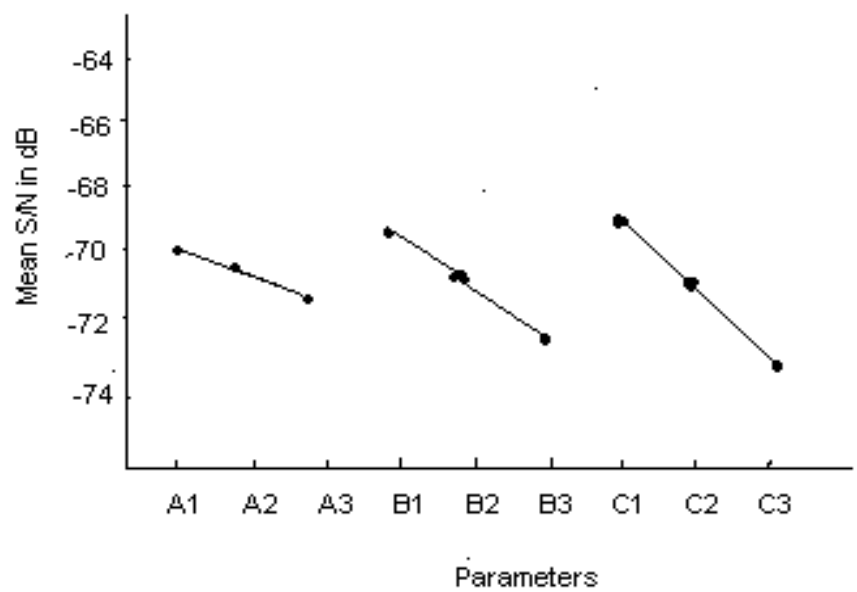

Figure 3: $\quad$ Main effect chart. 
Figure 3 shows the $\mathrm{S} / \mathrm{N}$ response graph for the output characteristic (cost). As shown in Eqs. (7) and (8), the greater the $\mathrm{S} / \mathrm{N}$ ratio, the smaller is the variance of the output characteristic around the desired (the-lower-the-better) value. However, the relative importance amongst the parameters for cost still needs to be known so that optimal combinations of the parameter levels can be determined more accurately. This will be discussed in the next section using the analysis of variance.

\section{Results and discussion}

\subsection{Analysis of variance}

The purpose of the analysis of variance (ANOVA) is to investigate which design parameters significantly affect the quality characteristic. This is accomplished by separating the total variability of the $\mathrm{S} / \mathrm{N}$ ratios, which is measured by the sum of squared deviations from the total mean $\mathrm{S} / \mathrm{N}$ ratio, into contributions by each of the design parameters and the error. First, the total sum of squared deviations $\mathrm{SS}_{\mathrm{T}}$ from the mean $\mathrm{S} / \mathrm{N}$ ratio $\eta_{\mathrm{m}}$ is calculated as:

$$
\mathrm{SS}_{\mathrm{T}}=\sum_{i=1}^{n}\left(\eta_{i}-\eta_{\mathrm{m}}\right)^{2}
$$

where $\mathrm{n}$ is number of experiments in the orthogonal array, $\eta_{i}$ is the mean $\mathrm{S} / \mathrm{N}$ ratio for the ith experiment and $\eta_{\mathrm{m}}$ is the mean of $\mathrm{S} / \mathrm{N}$ ratio given in Table 4 .

The total sum of squared deviations SST is decomposed into two sources: the sum of squared deviations SSd due to each process parameter and the sum of squared error SSe. The percentage contribution $\mathrm{p}$ by each of the process parameter in the total sum of squared deviations SST is a ratio of the sum of squared deviations SSd due to each process parameter to the total sum of squared deviations SST.

Statistically, there is a tool called $\mathrm{F}$ test to see which process parameters have significant effect on the quality characteristic. The $\mathrm{F}$ value for is the ratio of the mean of squared deviations SSm to the mean of squared error SSe. Therefore for performing the F test, the mean of squared deviations SSm due to each process parameter needs to be calculated, which is equal to the sum of squared deviations SSd divided by the number of degrees of freedom associated with the process parameter. Usually, when $\mathrm{F}>4$, it means that the change of the process parameter has significant effect on the quality characteristic.

Table 6 shows the results of ANOVA for the cost. It can be found that the change of parameters in the range given in Table 2 has significant effect on the cost since for all parameters $\mathrm{F}$ value is greater than 4 . Therefore, based on the $\mathrm{S} / \mathrm{N}$ and ANOVA analyses, the optimal parameters are Pg1 at level 1, Pg2 at level 1, and Pg3 at level 1. However, the contribution order of the parameters for cost is Pg3 (69.55\%), then Pg2 (20.88\%), and then Pg1 (9.12\%). 
Table 6: $\quad$ Results of the ANOVA.

\begin{tabular}{|c|c|c|c|c|c|c|}
\hline Symbol & parameter & $\begin{array}{c}\text { Degree of } \\
\text { freedom }\end{array}$ & $\begin{array}{c}\text { Sum of } \\
\text { squares }\end{array}$ & $\begin{array}{c}\text { Mean } \\
\text { square }\end{array}$ & $\mathrm{F}$ & Contribution \\
\hline $\mathrm{A}$ & $\mathrm{P}_{\mathrm{g} 1}$ & 2 & 5.0859 & 2.5429 & 20.3827 & 9.12 \\
\hline $\mathrm{B}$ & $\mathrm{P}_{\mathrm{g} 2}$ & 2 & 11.6443 & 5.8222 & 46.667 & 20.88 \\
\hline $\mathrm{C}$ & $\mathrm{P}_{\mathrm{g} 3}$ & 2 & 38.7741 & 19.3871 & 155.3951 & 69.55 \\
\hline Error & & 2 & 0.2495 & 0.1248 & & 0.45 \\
\hline Total & & 8 & 55.75 & & & 100 \\
\hline
\end{tabular}

\subsection{Confirmation tests}

Once the optimal level of the design parameters has been selected, the final step is to predict and verify the improvement of the quality characteristic using the optimum level of the design parameters. The estimated $\mathrm{S} / \mathrm{N}$ ratio $\hat{\eta}$ using the optimal level of the design parameters can be calculated as:

$$
\hat{\eta}=\eta_{\mathrm{m}}+\sum_{i=1}^{o}\left(\bar{\eta}_{i}-\eta_{\mathrm{m}}\right)
$$

where $\eta_{\mathrm{m}}$ is the total mean $\mathrm{S} / \mathrm{N}$ ratio, $\bar{\eta}_{i}$ is the mean $\mathrm{S} / \mathrm{N}$ ratio at the optimal level, and $o$ is the number of the main design parameters that affect the quality characteristic.

The estimated $\mathrm{S} / \mathrm{N}$ ratio using the optimal parameters for the cost can be obtained and the corresponding cost can also be calculated by using Eqs. (8) and (9). Table 7 shows the comparison of the predicted cost with the actual cost using the optimal parameters. The predicted /estimated fuel cost is Rs 2172.9 per hour where as the actual cost obtained from the experiment is Rs 2140.70 per hour. The difference between these two costs is only Rs 32.2 per hour. This indicates that the experimental and estimated values are very close. And this confirms that the optimum levels of parameters are $\mathrm{P}_{\mathrm{g} 1}$ at Level $1, \mathrm{P}_{\mathrm{g} 2}$ at Level 1 and $\mathrm{P}_{\mathrm{g} 3}$ at Level 1. It further verifies that the experimental result is strongly correlated with the estimated result, as the error is only $1.48 \%$.

Table 7: $\quad$ Results of confirmation experiment.

\begin{tabular}{|c|c|c|c|}
\hline & \multicolumn{2}{|c|}{ Optimal condition } & \multirow{2}{*}{ Difference } \\
\cline { 2 - 3 } & Estimation & Experiment & \\
\hline Level & $\mathrm{A}_{1} \mathrm{~B}_{1} \mathrm{C}_{1}$ & $\mathrm{~A}_{1} \mathrm{~B}_{1} \mathrm{C}_{1}$ & \\
\hline Fuel cost & 2172.9 & 2140.70 & 32.2 \\
\hline S/N value & -66.74 & -66.61 & 0.13 \\
\hline
\end{tabular}

\section{Conclusion}

Application of Taguchi method to minimize the cost function in solving the economic dispatch problem is presented in this paper. An orthogonal array, the 
signal-to-noise $(\mathrm{S} / \mathrm{N})$ ratio and the analysis of variance (ANOVA) are employed to obtain the optimal level of the parameters involved in minimizing the cost function. The results show that the Taguchi method is insensitive to the choice of initial values for parameters and the results obtained is approximately equal to the minimum cost irrespective of the chosen values of the level of parameters. The optimized results have also been verified using the confirmatory test. It is observed that the Taguchi method is quite simple and effective tool in providing a satisfactory solution to the optimization problems.

\section{References}

[1] Mohatram M., Kumar S., "Application of Artificial Neural Network in Economic Generation Scheduling of Thermal Power Plants" Proceedings of the National Conference on Recent Trends in Information Technology, Ibra College of Technology, Sultanate of Oman, pp 114-117. May 17-18, 2006

[2] Eiklenborg M., Ioannou S., Gregory K., Vilcheck M., "Taguchi Methods for Achieving Quality" Project I,ENGR 801 - Engineering Management, San Francisco State University, School of Engineering.

[3] Cai Y., Liu D., "An Orthogonal Array Optimization for the Economic Dispatch with Non-smooth Cost Functions. 44th IEEE conference on decision and Control, and the European control conference 2005, Seville, Spain. pp 1264-1269. Dec 12-15, 2005

[4] B. H. Lee, J. Abdullah, Z. A. Khan, “Optimization of rapid prototyping parameters for production of flexible ABS object "Journal of Materials Processing Technology, pp.54-61. 169 (2005)

[5] Cai Y., Liu D., "Multi-user Detection Using the Taguchi Method For DSCDMA Systems", IEEE Transaction on Wireless Communications, Vol.4, No.4,.pp.1594-1607. July 2005

[6] Liu D., Cai Y., "Orthogonal Array Optimization Method for multi-user Detection in DS-CDMA Systems". 44th IEEE conference on Decision and control, and the European control conference 2005. Seville, Spain, pp.1885-1889. December 12-15, 2005

[7] W. H. Yang, Y. S. Tarng, "Design optimization of cutting parameters for turning operations based on the Taguchi method", Journal of Materials Processing Technology, Vol. 84, , pp. 122-129. 1998

[8] Ranjit K. Roy "A Primer on the Taguchi Method" Competitive Manufacturing Series, Van Nostrand Reinhold, New York. 1999

[9] C. L. Wadhwa,"Power System Optimization". WeilyEastern publication, 1993

[10] Arthur R. Bergen, Vijay Vittal, "Power System Analysis" Pearson Education Asia Publication, 1991. 